\title{
Carbon-14 Tracer Study of Polyacrylate Polymer in a Wastewater Plant
}

\author{
JAMES E. MARTIN, ${ }^{1, *}$ THOMAS STEVENS, ${ }^{2}$ GORDON E. BELLEN, ${ }^{2}$ \\ LARRY W. KING ${ }^{3}$ and JAMES M. HYLKO
}

${ }^{1}$ School of Public Health, University of Michigan, Ann Arbor, MI 48109, ${ }^{2}$ National Sanitation Foundation, Ann Arbor, MI 48105, ${ }^{3}$ The Procter and Gamble Company, 6100 Center Hill Road, Cincinnati, OH 45224 and ${ }^{4}$ Fluor Daniel, Inc., 200 West Monroe Street, Chicago, IL 60606, U.S.A.

(Received July 1989)

\begin{abstract}
A highly absorbent consumer-product, polyacrylate-polymer material tagged with carbon-14 $\left({ }^{14} \mathrm{C}\right)$, was dosed to a standard on-site aerobic wastewater treatment plant which contained a settling chamber, an aeration chamber, and an effluent chamber. Operation of the test plant was essentially the same as that of a control plant even under exaggerated conditions. About $97 \%$ of the polymer material was retained in solids deposited in the primary and aeration chambers, and effluent releases were minimal. The use of a ${ }^{14} \mathrm{C}$ tagging procedure proved to be a successful method for studying the behavior of these complex materials. It may be useful to conduct a further study on retaincd solids to determine whether microbial decomposition of the polymer material occurs while they remain in typical plants.
\end{abstract}

\author{
Notation \\ AC-aeration chamber \\ $\mathrm{BOD}_{5}$ - biochemical oxygen demand, 5-day technique \\ COD chemical oxygen demand \\ E-effluent \\ LS-liquid scintillation \\ mCi-millicurie \\ MLSS-mixed liquor suspended solids \\ NSF - national sanitation foundation \\ PC-primary chamber \\ $\mathrm{pCi}$-picocurie \\ SL-sludge \\ SN-supernate \\ SS--suspended solids \\ VSS-volatile suspended solids \\ 57 -refers to plant 57 , the test plant \\ 58 -refers to plant 58 , the control plant
}

\section{Introduction}

A number of highly absorbent consumer products are currently being developed which use fiber components to which highly absorbent polymers are added. The high absorbency of these products without large bulk may make these products very popular, leading to a number of questions on the environmental effects of their disposal. The discharge of such products into on-site wastewater treatment systems such as septic tanks or aerobic treatment systems has, on occasion, been alleged to cause upset or failure of these systems. Upset or failure of these systems could result in

*Author for correspondence [Tel. (313) 936-0763]. unacceptable discharges of pollutants; thus, it is important to assess the fate and effect of these products when they are disposed into on-site wastewater systems. This study was undertaken to determine whether an absorbent fiber product would have a significant adversc effect on the operation of an aerobic on-site wastewater treatment unit, and to measure the retention and migration of a ${ }^{14} \mathrm{C}$-tagged polyacrylate-polymer ingredient of the fiber product introduced into the same treatment unit. This paper deals specifically with the fate of the polymer product disposed in a typical on-site wastewater treatment unit; other environmental studies of the polymer are being conducted elsewhere (King, 1986).

\section{The Test Facility}

The study was conducted at the Wastewater Technology Test Facility operated by the National Sanitation Foundation (NSF) in the Village of Chelsea, Michigan. The facility is owned and operated by NSF for testing a variety of wastewater treatment devices, primarily to determine compliance with NSF Standards and for special studies. The Chelsea plant has an essentially domestic wastewater, collected almost entirely from homes and commercial buildings, with only a minor industrial component.

Raw wastewater for loading the treatment plants is obtained from an interceptor at the village wastewater treatment plant using an in-line diverter and an 8 -in. branch sewer. The sewage flows through a $\frac{1}{4}$-in. 
slot comminuter, is pumped through the dosing loop in the control building, and the unused portion is returned to the village interceptor. The electrical dosing controls in the dosing loop permit delivery of specific sewage volumes to individual tanks which then discharge the discrete doses to the plants being tested. This special dosing equipment allows simulation of various domestic wastewater flow patterns. The effluent from the test plants, and other wastewater generated at the Chelsea facility, is returned to the village interceptor for treatment at the Chelsea sewage treatment plant (Fig. 1).

Two identical residential aerobic-treatment plants were used in this study. The plants are aeration-activated sludge plants, designated as the test plant (plant 57) and the control plant (plant 58). These plants (EPA, 1980) conform with Class II requirements of NSF Standard 40 (NSF, 1983b), and are capable of meeting effluent requirements of $100 \mathrm{mg} / \mathrm{L}$ for suspended solids and $60 \mathrm{mg} / \mathrm{L}$ for $\mathrm{BOD}_{5}$. The plants are constructed of precast concrete and installed below ground (Metcalf and Eddy, 1972).

The test plants contain three compartments, as shown in Fig. 2. The first compartment is the primary chamber which receives the influent to the plant. Grit and large organic and inorganic solids settle out in the primary chamber which has a capacity of $475 \mathrm{gal}$. Some anaerobic degradation occurs in this chamber. The opening from the primary chamber to the aeration chamber is baffled to prevent passage of grease and other floating materials from the primary chamber.
Flow from the primary chamber goes to the second compartment which is a 600 -gal aeration chamber in which the wastewater is mixed with biomass and aerated. A mechanical aerator is mounted above the chamber in a concrete riser exposed above grade. The aerator consists of an electric motor coupled to a hollow shaft with an aspirator on the bottom. The aspirator and part of the shaft are submerged in the wastewater/sludge mixture. Rotation of the aspirator induces mixing, and a pressure differential is established which draws air from an intake on top of the riser down to hollow shaft. As air is injected into the tank contents, tiny bubbles are dispersed radially from the aspirator. Oxygen is introduced into solution by this process and biolugical degradation of organic matter occurs.

The third compartment, with a capacity of $150 \mathrm{gal}$, is a clarifier in which solids are separated from the treated wastewater. A baffle separating the aeration and clarifier compartments is open at the bottom, resulting in an upflow of the treated wastewater through the clarifier. The clarifier compartment has a sloping end wall that guides settled solids back into the aeration compartment. Quiescence in the clarifier is enhanced by a tube settler insert, approx. $1 \mathrm{ft}$ deep, that eliminates crosscurrents just beneath the fluid surface. At the top of the baffle, between the clarifier and aeration compartments, there is a 4-in. port that leads to a 1 -ft long pipe with a tee at the end. The pipe extends into the aeration chamber so that flow occurs from the clarifier to the aeration compartment. The function of the pipe is to skim floating material on the

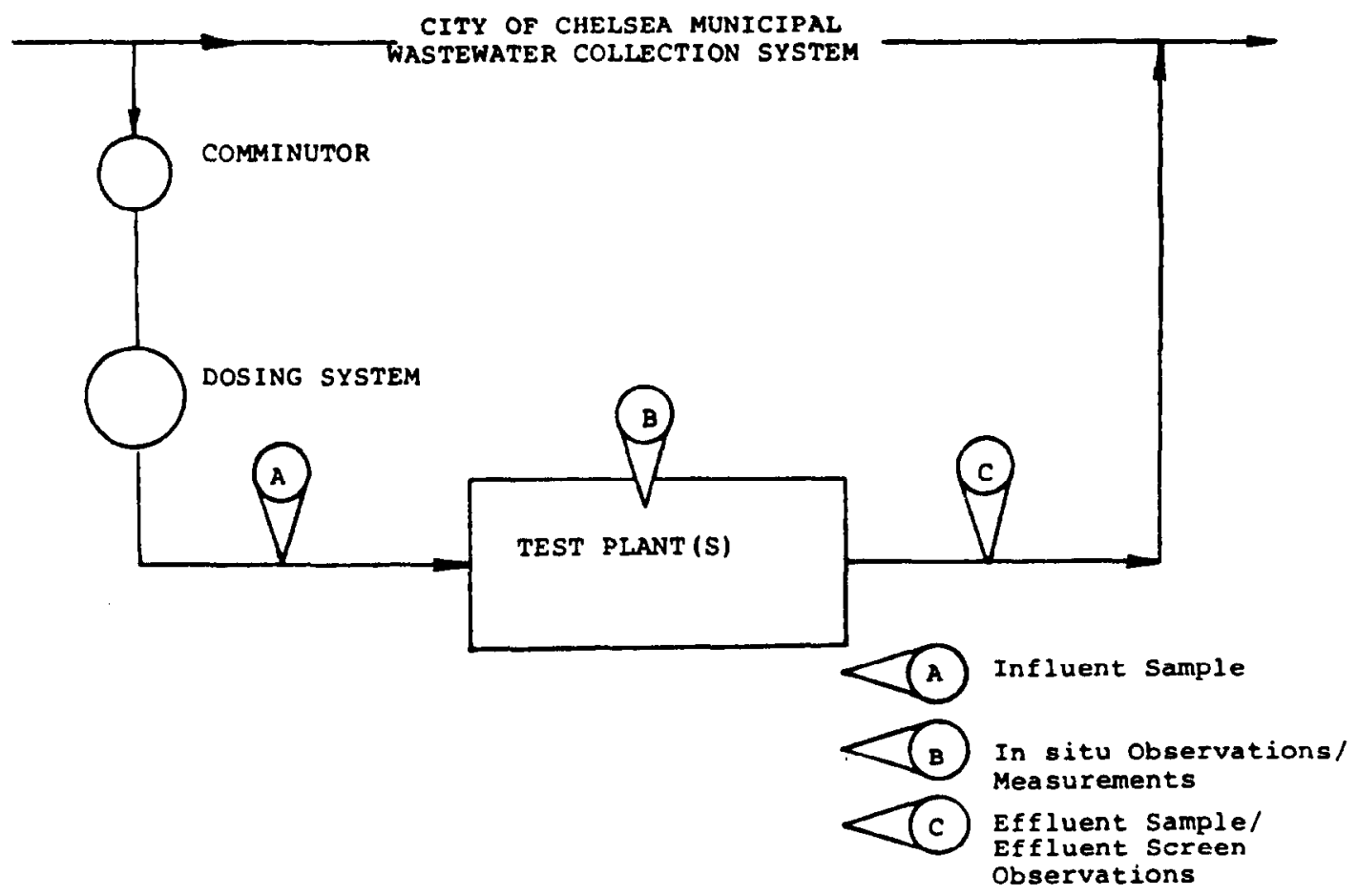

Fig. 1. Sampling diagram of wastewater test loop, Chelsea, Mich., wastewater collection system. 


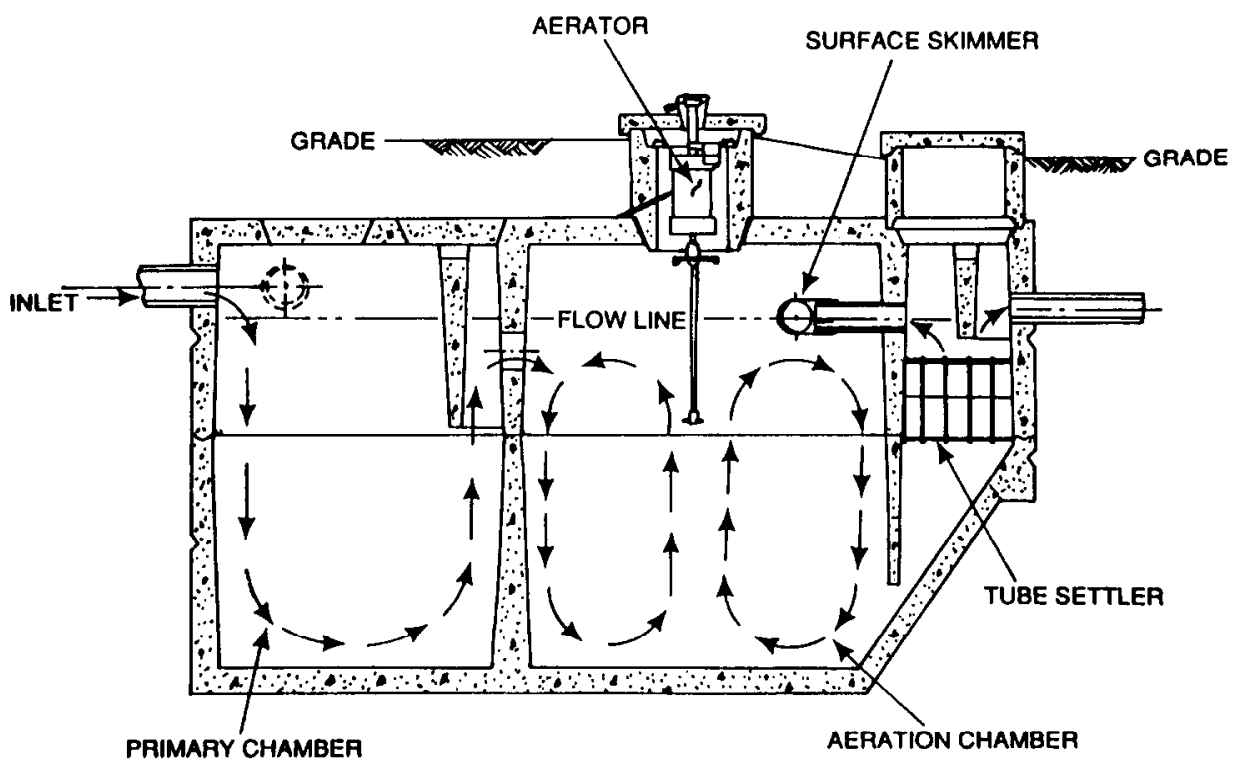

Fig. 2. Typical home aerobic-treatment plant.

clarifier, returning it to the aeration compartment for further treatment. Opposite the skimmer port is the effluent port, surrounded by a baffle extending 3 in. under the clarifier surface. The baffle prevents floating material from leaving the plant with the effluent.

Influent-sampling provisions were made at the influent dosing loop from which the wastewater was drawn and delivered to the plants. Insulated sampling stations were constructed in the effluent line from each plant to permit sampling and observation. $A \frac{1}{4}$ in. hardware cloth screen was installed in the effluent lines to collect large solids (in this study, parts of absorbent material or sludges) discharged from the plants. Influent and effluent sampling points (shown in Fig. 3) were equipped with automatic samplers programmed to composite samples in proportion to flow.

\section{Method}

A test plant and a control plant were filled with water and placed into operation. Wastewater was dosed to the plants for 6 weeks to allow for a buildup of biomass in the aeration chamber. The effluents of both plants were sampled and analyzed for $\mathrm{BOD}_{5}$,
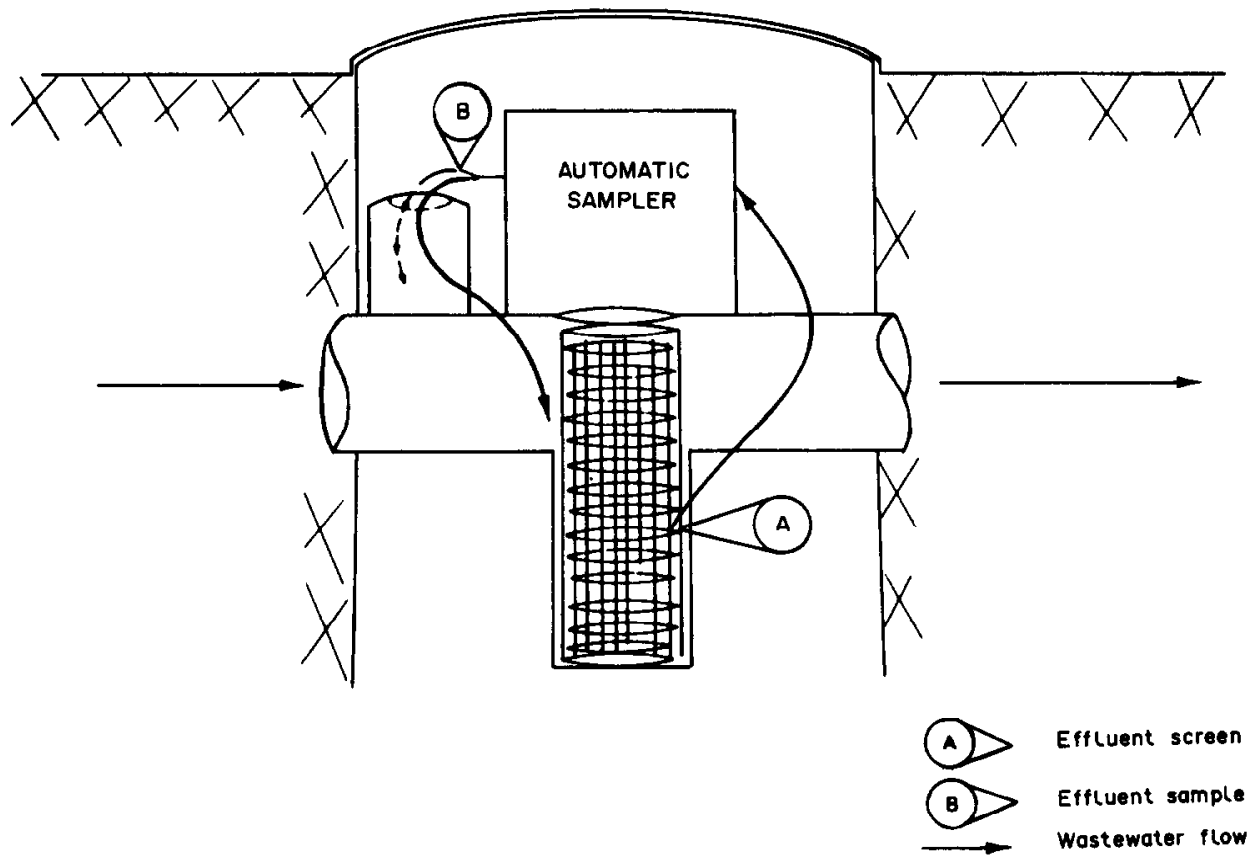

Fig. 3. Schematic of automatic sampler for treatment-plant effluent. 
COD, SS, VSS and cellulose to establish equivalent treatment performance by both (NSF, 1983a,b). Raw sewage was supplied daily to the plants in 40 doses of 6.25 gal each, equivalent to 250 gal per day, a daily flow rate typical of a family of five. The timed controlled dosing pattern was identical to that required in NSF Standard 40 which simulates flow from individual homes.

Non-radioactive fiber products were dosed to the plants for 32 weeks at the maximum anticipated usage rate of the products, with each plant receiving and equivalent amount of fiber material. The difference between the test product and the control product was the addition of an absorbent polymer to the test product. During the first 5 months of the study, the test plant generally achieved a better effluent than the control plant, producing an effluent typical of a home aerobic-treatment plant. The control-plant effluent closely paralleled the test-plant effluent during the first 3 months, but had higher effluent $\mathrm{BOD}_{5}$, COD and SS concentrations during the next 2 weeks. The effluent quality of both plants deteriorated over the final 3 months as excessive solids buildup occurred in the plants. It was found that both products readily settled in the primary chamber of the plants, as noted by a rapid accumulation of solids in both primary chambers. Vigorous anaerobic activity in the testplant primary chamber accounted for greater solids depths in the control-plant primary chamber than in the test-plant chamber. During the same period, the mixed-liquor suspended solids (MLSS) in the testplant aeration chamber increased at a greater rate than in the control plant because the greater anaerobic activity in the test-plant primary chamber resulted in greater solids loading to the test-plant aeration chamber. The MLSS in both plants increased to a point where the clarifier capacities were exceeded, resulting in an uncontrolled loss of solids from both plants. Such a buildup and uncontrolled solids loss is typical of home aerobic systems. The earlier and more vigorous anaerobic activity in the test-plant primary chamber, combined with an initially lower MLSS concentration in the test-plant aeration chamber, led to the conclusion that more organic solids were settled in the primary chamber of the test plant than in the control plant.

\section{Carbon-14 tracer study}

In order to determine the fate of the polymer and the amounts retained in the various parts of the plant, a study was undertaken using ${ }^{14} \mathrm{C}$-labelled polymer similar to that used in the test product. The presence of ${ }^{14} \mathrm{C}$ in the plant effluent and in-plant sludges and supernatants would indicate the fate of the polymer after dosing to the plant. The test-product material is proprietary, but is described as a lightly cross-linked, high-molecular-weight polyacrylate polymer. The polymer is highly absorbent and appears to be quite stable with little depletion of ${ }^{14} \mathrm{C}$ activity due to physical, chemical, or biological processes. The test product dosed to the test tanks was a pad made of cellulose fibers into which was mixed a small quantity of polyacrylate-polymer powder labelled with ${ }^{14} \mathrm{C}$ in such a way that the ${ }^{14} \mathrm{C}$ atoms are bound repeatedly along the long-chained molecular structure, i.e. on the backbone of the polymer molecule. The control product was a pad of cellulose fibers with no polymer added.

The ${ }^{14} \mathrm{C}$-tagged polymer was dosed to the test plant over a 2-day period during week 33 of the study. Approximately $440 \mathrm{mg}$ (four $110-\mathrm{mg}$ vials) of polymer were added each day. The concentration of ${ }^{14} \mathrm{C}$ in the polymer was $5.7 \mathrm{mCi} / \mathrm{g}$, with each vial having an activity of $0.627 \mathrm{mCi}$. The dosed material was prepared with dry polymer by mixing with water to form a suspension having a polymer concentration of $1000 \mathrm{mg} / \mathrm{L}$. The mixture was prepared a day in advance of dosing to allow for complete hydration of the polymer. The mixture was added to the plant influent dose prior to addition of the scheduled fiber product (cellulose fiber plus non-labelled polymer) dose in order to allow the polymer to be carried to the plant with the fiber product. Fiber-product dosing of the plants continued for 28 days following the 2 days of polymer addition. The test plant continued receiving four doses per day of the fiber product, while the control plant received five doses per day of the control product. Samples were taken of the effluent from the test plant on a daily basis for the first 12 days of the study, and less frequently thereafter. Samples were also taken of the aeration chamber on the second, tenth and 28th day of the study. The test continued until week 37 of the study. All influent to the plants was stopped and the plants were allowed to settle and stabilize for about 8 weeks, after which the settling chambers were sampled to establish a balance between ${ }^{14} \mathrm{C}$ activity added and that which was discharged or retained in the plant solids.

\section{Carbon-14 measurements}

Samples were analyzed for ${ }^{14} \mathrm{C}$ radioactivity which was presumed to be directly proportional to the amount of polymer material present. Liquid samples with little solids were analyzed by adding $4 \mathrm{~mL}$ (about $20-25 \%$ by volume) directly to a LS cocktail in standard $20-\mathrm{mL}$ scintillation vials. Those samples that contained too great a solids content for direct LS counting were analyzed by a combustion procedure (Martin, 1986), as shown in Fig. 4. This method used a ceramic sample holder which was inserted into a tube furnace for $2 \mathrm{~h}$ at about $800^{\circ} \mathrm{C}$. The ceramic tube was packed at the downstream end with copper oxide catalyst which was also maintained at $800^{\circ} \mathrm{C}$. Carbon in the sample was driven off by the heat and was converted to carbon dioxide when passed through the heated catalyst packing. The ${ }^{14} \mathrm{CO}_{2}$ gas was routed by vacuum flow through two fritted-glass bubblers (one is used as a backup) containing about $20 \mathrm{~mL}$ of LS solution which contains chemicals specifically formulated for trapping ${ }^{14} \mathrm{CO}_{2}$. After the sample is 


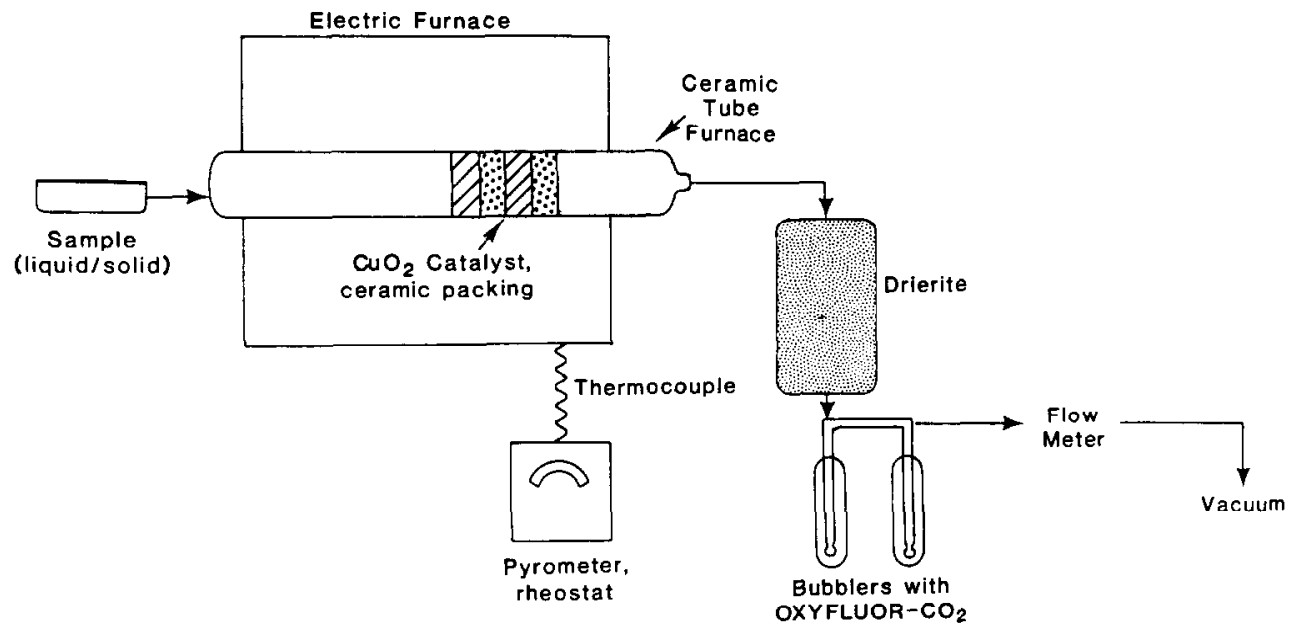

Fig. $4 .{ }^{14} \mathrm{C}$ combustion apparatus.

combusted, the bubbler solution is transferred to tandard scintillation vials for counting in a liquidcintillation analyzer. The fritted-glass bubbler was leaned before processing another sample, and peridic memory checks were run with blanks to assure consistency of background levels. If the background evel increased significantly, the furnace was left on or about a day to reduce the level, or if the procedure was unsuccessful, the tube was repacked or replaced.

Several measurements were made using standardzed polymer to establish the conversion efficiency, which was about $50 \%$ for a 2 -h combustion period. It the beginning of the study it was uncertain how eliable direct LS counting of samples would be since the ${ }^{14} \mathrm{C}$ was bound to polymers which could distort the low-energy $\beta$-particle spectrum of ${ }^{14} \mathrm{C}$. For this leason, several duplicates were run using both direct IS counting and combustion analysis, which was ilssumed to be the method of reference. Periodic cross hecks were also made of direct LS analyses as the study proceeded, and in general, direct LS analysis vas found to be reasonably consistent, though giving :omewhat lower results than combustion analyses, as jong as solid content was not excessive. Combustion ivas performed on all filtered residues and sludge samples.

\section{Results}

The radioactivity concentrations measured by the I.S and combustion procedures are summarized in Table 1 by sampling date and sample source. The LS and combustion data were obtained by using 4-mL ciliquots. The filter-residue results were based on filtering $30-\mathrm{mL}$ aliquots of the sample and analyzing the filtrate by direct LS analysis; the residues were analyzed by combustion. Theoretically, the ${ }^{14} \mathrm{C}$ activity obtained by LS and by combustion of samples should be equal; however, solids present in the samples cause the LS activity measurements to be lower than those obtained by the combustion procedure. This effect also explains why the LS activities for total samples are less than the sum of the activity measured in filtrate and filter residues, as would be expected. In spite of the problem, the LS activity data provide good information about the activity of the polymer in the plants.

The filtrate and filtered residue data provide information about the relative portion of the polymer in the sample that is associated with solids. Samples were analyzed for ${ }^{14} \mathrm{C}$ content in the effluent from the test plant, the aeration chamber of the test plant, and the effluent from the control plant. Nine samples of the effluent from the test plant were analyzed during the first 12 days of the study. Figure 5 shows the activity-concentration data obtained from the filtrate and filter residue, and the sum of the two, representing the total for the sample. The presence of steadily increasing amounts of polymer in the effluent, peaking at 5 days (the hydraulic retention time in the plant of $250 \mathrm{gal} /$ day flow rate is about $4 \frac{1}{2}$ days), indicates that there was good dispersion of the polymer in the plant. The presence of low and then decreasing concentrations of polymer in the filtrate, coupled with the high percentage of effluent polymer associated with solids (Fig. 6), indicates that the polymer was almost entirely bound with solids.

The amount of polymer leaving the plant was estimated using the ${ }^{14} \mathrm{C}$ concentration data and plant flow rates during the period. The approximate amount of polymer remaining in the plant was calculated using mass-balance techniques. About 3\% of the total amount of polymer dosed to the plant had been discharged in the effluent (about $80 \%$ associated with solids) after 10 days, and about $97 \%$ of the polymer remained in the plant.

During the study, two grab samples were taken from the aeration chamber of the test plant and filtered for analysis of the filtrate and filter residue. The first sample was taken on day 2 of the study and 
Table 1. Measured activity-concentrations of ${ }^{14} \mathrm{C}$ in effluent, sludge, filtered solids, and filtrates of the test plant and control plant

\begin{tabular}{|c|c|c|c|c|c|c|c|}
\hline \multirow[b]{2}{*}{ Date } & \multirow[b]{2}{*}{$\begin{array}{c}\text { Study } \\
\text { date }\end{array}$} & \multicolumn{2}{|c|}{ Total sample } & \multicolumn{4}{|c|}{ Filtered sample } \\
\hline & & $\begin{array}{l}\text { Sample } \\
\text { source* }\end{array}$ & $\begin{array}{l}\text { LS count } \\
(\mathrm{pCi} / \mathrm{mL})\end{array}$ & $\begin{array}{c}\text { Combustion } \\
(\mathrm{pCi} / \mathrm{mL})\end{array}$ & $\begin{array}{r}\text { Filter } \\
\text { (pCi/g) }\end{array}$ & $\begin{array}{l}\text { residue } \\
(\mathrm{pCi} / \mathrm{mL})\end{array}$ & $\begin{array}{c}\text { Filtrate } \\
(\mathrm{pCi} / \mathrm{mL})\end{array}$ \\
\hline $2 / 4$ & 1 & E57 & 1.03 & 5.7 & $\ldots$ & - & - \\
\hline $2 / 5$ & 2 & AC57 & 39.2 & 60.1 & 30,284 & 58 & 6.5 \\
\hline $2 / 5$ & 2. & F.57 & 4.1 & 6.5 & 8346 & 1.8 & 3.6 \\
\hline $2 / 5$ & 2 & E58 & 0.03 & 1.9 & 3166 & 0.2 & 0.5 \\
\hline $2 / 6$ & 3 & E57 & 12.4 & & 92,000 & 4.0 & 5.0 \\
\hline $2 / 7$ & 4 & E57 & 14.0 & 11.9 & 60,312 & 6.2 & 4.9 \\
\hline $2 / 8$ & 5 & E57 & 40.7 & 35.4 & 54,420 & 28.8 & 5.6 \\
\hline $2 / 9$ & 6 & E57 & 21.6 & 16.1 & 62,671 & 23.2 & 1.7 \\
\hline $2 / 10$ & 7 & E57 & 6.3 & & 84,319 & 8.7 & 2.7 \\
\hline $2 / 11$ & 8 & E57 & 23.1 & 32.8 & 30,933 & 20.4 & 1.2 \\
\hline $2 / 12$ & 9 & E57 & 4.1 & 13.6 & 105,887 & 14.1 & 0.8 \\
\hline $2 / 13$ & 10 & E57 & 7.1 & & & & \\
\hline $2 / 14$ & 11 & E57 & 5.2 & 7.9 & 26,800 & 1.0 & 3.8 \\
\hline $2 / 14$ & 11 & $A C 57$ & 1.5 & & & & \\
\hline
\end{tabular}

"E-effluent; AC-aeration chamber; SL-sludge; SN-supernate; PC-primary chamber: 57-Plant 57; 58-Plant 58. SN and SL samples were taken from the PC.

tFlow to both plants stopped on $3 / 6$; settled materials in the plant chambers were sampled on $5 / 10$.

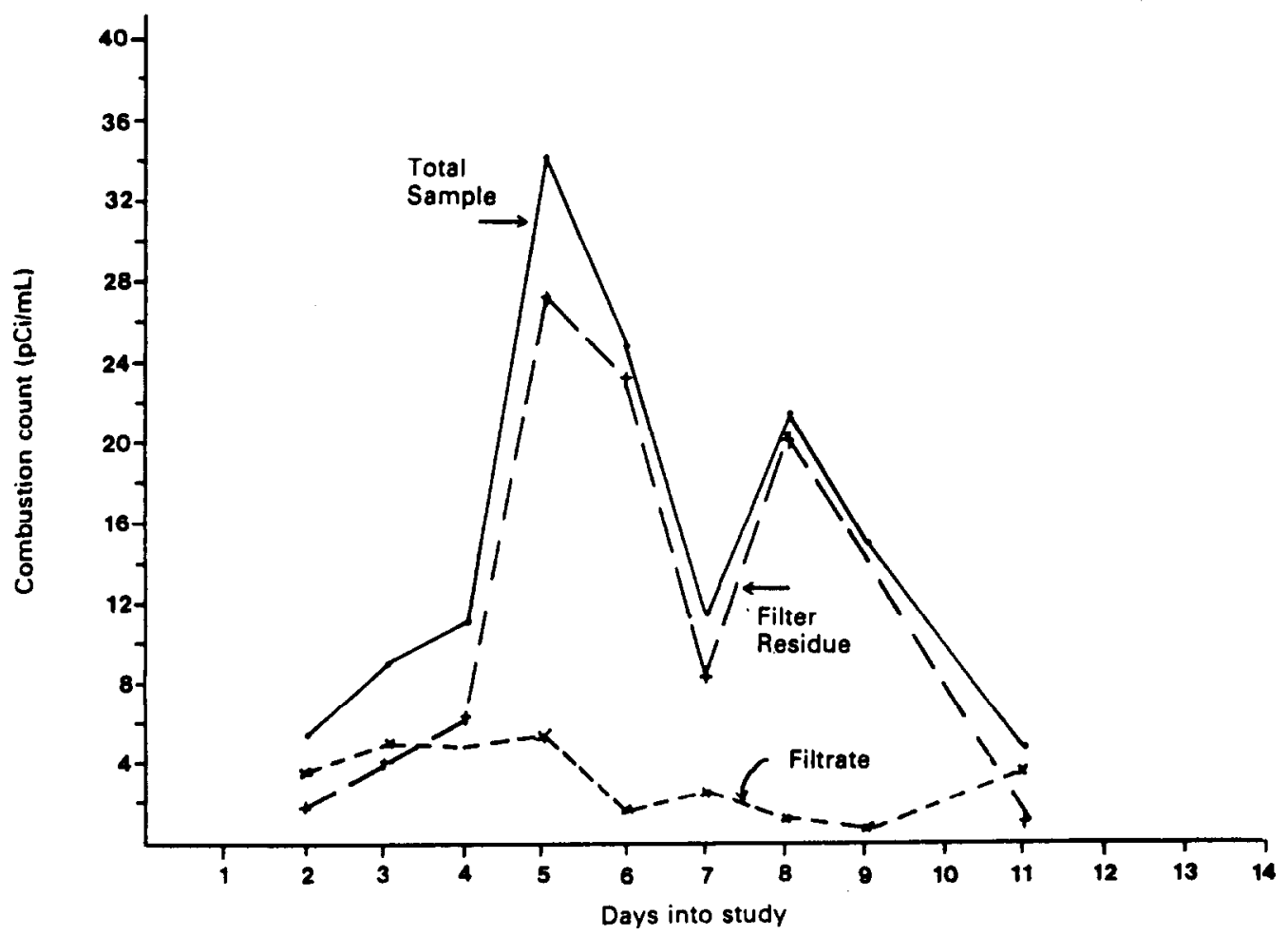

Fig. 5. Measured ${ }^{14} \mathrm{C}$ activity-concentrations (combustion method) in test plant 57 effluent. 


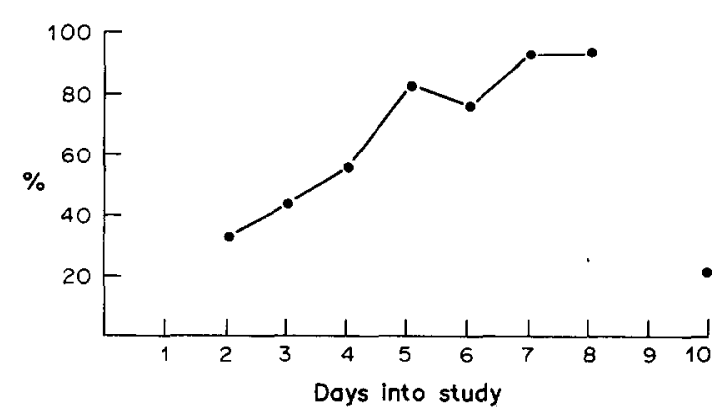

Fig. 6. Percentage of polymer associated with solids in effluent from test plant 57

the second on day 30 . The sample taken on day 2 showed about $90 \%$ of the polymer associated with the solids. The amount of polymer in the aeration chamber was estimated based on the ${ }^{14} \mathrm{C}$ activity concentration in the sample and the volume of the aeration chamber. It was assumed that the radioactivity in the aeration chamber was completely mixed, which yielded a calculated value of about $7 \%$ of the first-day polymer dose being retained in the ieration chamber. With less than $1 \%$ of the first-day dose accounted for in the plant effluent on day 2 , more than $90 \%$ of the first-day's dose appears to have been retained in the primary chamber. The second sample, taken after 30 days of operation, showed Ilmost all of the polymer (99\%) associated with the ;olids.

Upon completion of the 30-day study period, product addition and wastewater dosing of the two olants was stopped, and the plants were allowed to sit dle for 2 months, with only aeration provided. The sontents of both plants were then thoroughly mixed ind samples were taken from the primary and aeraion chamber of the test plant and from the aeration hamber of the control plant. A portion of each ample was analyzed by the combustion method to neasure the ${ }^{14} \mathrm{C}$ activity concentration, and a portion was filtered for analysis of the filtrate and filter esidue. The analysis of the filtrate and filter residue ndicated that $99.8 \%$ of the polymer in the primary thamber was associated with solids; $99.5 \%$ of that in he aeration chamber was in the solids.

The combustion data for the samples from the test plant provide information about the amount of polyner remaining in each tank at the end of the study. .t was assumed that the amount in the tank was

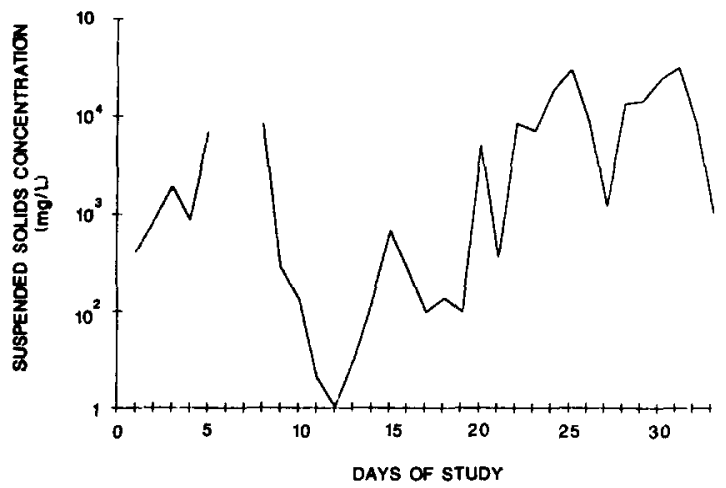

Fig. 7. Suspended-solids concentration in test-plant 57 effluent.

consistent since the polymer has been shown to be non-biodegradable in laboratory experiments (King, 1986). This assumption was supported by batch aqueous aerobic biodegradation studies (King, 1986); the $\mathrm{CO}_{2}$ measured was less than $6 \%$ of the amount that would be expected if biodegradation were present. The amount of polymer in each chamber was calculated, using the ${ }^{14} \mathrm{C}$ correlation data for sludge and the volume of each chamber. The primary chamber had a total of $0.239 \mathrm{mCi}$, which represents about $5 \%$ of the total amount of polymer added. The aeration chamber contained $1.50 \mathrm{mCi}$, or about $30 \%$ of the polymer dosed to the plant. Thus, roughly $35 \%$ of the initial polymer dose $(5.02 \mathrm{mCi})$ was retained in the treatment plant.

A mass balance of the amount of polymer discharged in the plant effluent was quantified using the data on effluent suspended solids for the test plant shown in Fig. 7. The unusually high concentrations of solids in effluents were attributed to high loadings of fiber-based product during the previous 5 months of the study. Average influent and effluent data for the previous 5 months are shown in Table 2 and are more typical of the performance of this plant design. The rapid accumulation of solids caused by the accelerated product loading resulted in sporadic losses of solids through the plant.

A linear regression was completed to determine if a correlation existed between the effluent suspended solids and the LS data obtained for effiuent samples from the test plant. Other correlations, such as the LS data to volatile suspended solids, combustion data to suspended and volatile suspended solids, and log LS

Table 2. Influent and effluent wastewater quality prior to tracer loading (mg/L)

\begin{tabular}{|c|c|c|c|c|}
\hline & \multicolumn{2}{|r|}{ Influent } & \multicolumn{2}{|r|}{ Effluent } \\
\hline & Mean & $\begin{array}{l}\text { Coefficient } \\
\text { of variation* }\end{array}$ & Mean & $\begin{array}{l}\text { Coefficient } \\
\text { of variation* }\end{array}$ \\
\hline Suspended solids & 244 & $0.65 \%$ & 63 & $0.54 \%$ \\
\hline Volatile suspended solids (\%) & 76 & 0.18 & 77 & 0.16 \\
\hline Chemical oxygen demand & 339 & 0.19 & 98 & 0.24 \\
\hline Biochemical oxygen demand & 179 & 0.40 & 31 & 0.56 \\
\hline Cellulose & 82 & 0.39 & 31 & 0.41 \\
\hline
\end{tabular}

*One-hundred times the estimated standard deviation divided by the mean $(100 s / \bar{x})$. 
data to log solids, were also investigated. The correlation between effluent suspended solids and the LS data provided the best correlation $(r=0.87)$. Missing LS data points were estimated using the suspendedsolids data for the missing dates and inserting them into the equation derived in the linear regression. The total polymer accounted for in the plant effluent was calculated from the actual and projected LS data. The total amount of polymer in the effluent was estimated to be about $19 \%(0.961 \mathrm{mCi})$ of the amount dosed to the treatment plant. In total, $54 \%$ of the polymer dosed to the plant is accounted for, about $65 \%$ of which was retained in the plant.

Samples were taken from the control plant and analyzed even though it had not received labelled polymer. Data for three effluent samples showed activity concentrations ranging from 0.03 to $1.9 \mathrm{pCi} / \mathrm{mL}$. A sample from the aeration chamber, taken after the plant had been idle for 2 months, was analyzed by the combustion method and had an activity-concentration level of $2.26 \mathrm{pCi} / \mathrm{mL}$. These control plant levels are very low and are within the detection variability of the measuring system; they may also represent residual radioactivity in the system due to processing of higher-activity samples or naturally-occurring radionuclides.

\section{Summary and Conclusion}

The disposal of highly-absorbent fiber-based consumer products in on-site wastewater treatment plants is likely to increase considerably as these products receive wider use by the public. Such disposal appears to produce minimal adverse effects on the operation of typical wastewater plants because effluent levels were shown to contain very small fractions of the material placed in a typical aerobic system. Most of the polyacrylate-polymer material studied remained with the solids, which for the most part were retained in the primary and aeration chambers of the study plant even under exaggerated test conditions. The use of ${ }^{14} \mathrm{C}$ as a radioactive tracer proved to be an effective study technique for determining engineered performance of the wastewater plant, the amount of products released in effluents, and the amount retained in solids removed by the plant.

\section{References}

EPA (1980) Design Manual-Onsite Wastewater Treatment and Disposal. U.S. EPA, Washington, D.C.

King L. W. (1986) Personal communication, Procter and Gamble Company, Cincinnati, Ohio.

Martin J. E. (1986) Carbon-14 in low-level radioactive waste from two nuclear power plants. Health Phys. 50, $57-64$.

Metcalf \& Eddy, Inc. (1972) Wastewater Engineering: Collection, Treatment, Disposal. McGraw-Hill, New York.

NSF (1983a) Chemistry Laboratory Quality Control Manual. National Sanitation Foundation, Ann Arbor, Mich.

NSF (1983b) Standard 40 for Individual Aerobic Wastewater Treatment Plants. National Sanitation Foundation, Ann Arbor, Mich. 